\title{
Impact of thermoclines on the vertical distribution of salmon lice larvae
}

\author{
T. Crosbie ${ }^{1}$, D. W. Wright ${ }^{2}$, F. Oppedal ${ }^{2}$, S. Dalvin ${ }^{2}$, M. S. Myksvoll ${ }^{2}$, T. Dempster ${ }^{1, *}$ \\ ${ }^{1}$ Sustainable Aquaculture Laboratory - Tropical and Temperate (SALTT), School of BioSciences, University of Melbourne, \\ Victoria 3010, Australia \\ ${ }^{2}$ Matre Aquaculture Research Station, Institute of Marine Research, 5984 Matredal, Norway
}

\begin{abstract}
Salmon louse Lepeophtheirus salmonis, a key parasite of salmonids, is managed by multiple methods at both salmon farm- and ecosystem-scale that are informed by an understanding of the abundance and distribution of the infective, planktonic stage of the lice. Dispersal modelling using hydrodynamic models relies on accurately estimating larval depth and how environmental variables modify distributions. Larval responses to temperature could modify dispersal distances by altering their depth in the water column and thus exposure to depth-dependent oceanographic processes and the duration of their temperature-dependent development. Using column experiments, we tested how $L$. salmonis nauplii and copepodids responded to different thermoclines by establishing a bottom layer of $12^{\circ} \mathrm{C}$ with an overlaying layer varying from 6 to $18^{\circ} \mathrm{C}$ in $2^{\circ} \mathrm{C}$ steps. Nauplii moved upwards in high proportions and aggregated in the surface layer when the overlying layer was $10^{\circ} \mathrm{C}$ or cooler. In contrast, nauplii moved downwards and aggregated at the thermocline when the overlying layer exceeded $12^{\circ} \mathrm{C}$. Temperature did not influence the vertical distribution of copepodids. When nauplii behaviour towards temperature was integrated into a dispersal model, dispersal distances increased. Temperature should be considered when calculating depth distributions. Further, nauplii and copepodids behave differently and should be configured separately in dispersal models.
\end{abstract}

KEY WORDS: Copepodid · Dispersal · Lepeophtheirus salmonis · Nauplii · Sea lice · Salmo salar · Temperature

\section{INTRODUCTION}

Marine plankton are found in all oceans at every conceivable depth. Their diel vertical migration has been described as the greatest migration on earth (Hays 2003). Specific environmental cues, such as light, salinity and temperature, can initiate and/or limit vertical migration (McLaren 1963, Haney 1988). Copepods, which are believed to be the most abundant metazoans on the planet (Mauchline 1998, Turner 2004), migrate to optimize feeding and therefore growth (Huntley \& Brooks 1982) and also minimize predation (McLaren 1963, Haney 1988, Lampert 1993). About half of the 10000 known species

*Corresponding author: dempster@unimelb.edu.au of marine copepods are parasitic, and parasitic larvae may have specific vertical migration strategies. In particular, when parasitic larvae reach the infective stage, they may seek to position themselves in the water column to maximize the chance of encountering and infecting a suitable host (Wootten et al. 1982, Heuch et al. 1995).

The salmon louse Lepeophtheirus salmonis is a common marine ectoparasite, living throughout the North Atlantic and Pacific Oceans, and principally infects salmonids. There are 8 life stages, beginning with planktonic non-parasitic nauplius I and II larvae, before development into the infective copepodid stage (Hamre et al. 2013). Salmon louse larvae are

() The authors 2020. Open Access under Creative Commons by Attribution Licence. Use, distribution and reproduction are unrestricted. Authors and original publication must be credited. 
lecithotrophic, with the nauplii and copepodid stages sustained by the energy reserves absorbed in the egg (Tully 1992). Copepodids must seek out and attach to a host before their energy reserves deplete.

Multiple environmental stimuli play a role in determining the vertical position of lice larvae in the water column. They are phototactic and will migrate upwards towards light if other influences are not present (Heuch et al. 1995, Aarseth \& Schram 1999, Crosbie et al. 2019), yet nauplii react to different wavelengths and are less sensitive to white light than copepodids (Novales Flamarique et al. 2000). Salinity also impacts lice behaviour, with both nauplii and copepodids displaying clear preferences for full salinity over brackish water when presented with a step gradient (Heuch 1995, Crosbie et al. 2019). Nauplii show greater avoidance of brackish water, while some copepodids may still be present in salinities of 20 ppt and below (Crosbie et al. 2019). While the vertical responses of lice larvae to light and salinity are well documented, there has been no empirical testing of responses to temperature. Some correlative field evidence suggests that nauplii, but not copepodids, may seek the highest possible seawater temperature in the water column in the absence of salinity stratification (á Norði et al. 2015).

Temperature is an important factor in determining development rates of marine larvae, which has implications for dispersal (O'Connor et al. 2007, Johnsen et al. 2014, Samsing et al. 2016). Salmon lice larvae grow and develop faster at warmer temperatures (Johnson \& Albright 1991, Angilletta et al. 2004, Samsing et al. 2016), with lower temperature limits identified where nauplii struggle to develop and moult into copepodids $\left(2-3^{\circ} \mathrm{C}\right.$ : Boxaspen \& Næss 2000). Just as for other lecithotrophic copepods in the nauplii stage, lice nauplii may be attracted to warmer layers in the water column to minimize development time and outgrow planktonic predators (McLaren 1963, Turner 2004). A possible drawback of rapid growth is that the infective copepodid stage is viable for a shorter period of time, as energy reserves are consumed faster (Boxaspen 2006, Samsing et al. 2016).

For salmon louse copepodids, temperature and infectivity are also correlated (Costello 2006). This is because infection encompasses attachment, exploration and fixation on the host-all activities that require active movement. If energy reserves have been depleted, infectivity is reduced (Tucker et al. 2002). While warmer water could assist in infecting a host by increasing activity, it also shortens the window of infectivity, thus reducing the likelihood of a host encounter. Maximizing the probability of host encounter may also mean that copepodids seek to match the vertical distribution of their hosts, which may conflict with positioning to optimize temperatures for maximum growth rate.

We aimed to determine the temperature preferences of the nauplii and copepodid stages of salmon louse larvae presented with step temperature gradients. We hypothesized: (1) that nauplii would be attracted to warmer temperatures, given their developmental needs and field-based evidence of their vertical distribution (á Norði et al. 2015); and (2) that copepodids would prefer warmer water but not as strongly as nauplii. We designed a column to present a choice between 2 layers of water with different temperatures. We tested overlying layers of $6,8,10$, $12,14,16$ and $18^{\circ} \mathrm{C}$ on top of a $12^{\circ} \mathrm{C}$ bottom layer in all columns. To test if the temperature preferences we detected might alter dispersal for a fjord-coastal area with intensive salmon farming, we compared the outputs of a pre-existing dispersal model with and without the effects of temperature.

\section{MATERIALS AND METHODS}

\subsection{Production of nauplii and copepodids}

We created a source population of sea lice to allow production of nauplii and copepodids for subsequent temperature experiments. Adult female salmon lice were sourced from salmon held at a commercial farm in western Norway $\left(60^{\circ} \mathrm{N}\right)$. Within the same day, lice were transferred to Atlantic salmon Salmo salar in tanks at the Matre Research Station at the Institute of Marine Research; 20-40 fish were held in 3 tanks at $12^{\circ} \mathrm{C}$ under natural light conditions and fed commercial food daily.

When harvesting eggs from lice, fish were captured and sedated with tricaine methanesulfonate (Finquel, Argent Chemical Laboratories) at a concentration of $1 \mathrm{~g}$ per $100 \mathrm{l}$ of water. Thereafter, eggs were transferred to an incubator system (as per Crosbie et al. 2019) and the number of egg strings and date of collection was recorded to determine larval age and lifecycle stage. Microscopy was used to identify stages if there was doubt.

\subsection{Experimental design and procedures}

To test larval behaviour around a thermal gradient, we designed a column experiment to simulate step temperature gradients based on previous studies 
looking at haloclines (Crosbie et al. 2019) and measured where the larvae preferred to distribute. We simulated thermoclines with an overlying layer ranging from 6 to $18^{\circ} \mathrm{C}$ on top of a bottom layer of $12^{\circ} \mathrm{C}$ and tested the depth preferences of both nauplii and copepodid stages.

We used 2 experimental columns which were glass tubes $85 \mathrm{~cm}$ long and $6 \mathrm{~cm}$ in diameter, contained within a hard plastic box housing (Fig. 1). The outer layer of the box was divided in half horizontally by $1 \mathrm{~cm}$ thick plastic and any gaps filled with sealer to create a watertight division between the top and bottom halves. White plastic half-pipes were fitted behind the glass columns to provide sufficient visual contrast to detect larvae. Columns were under a single $35 \mathrm{~W}$ cool white fluorescent light (Aarseth \& Schram 1999) placed $40 \mathrm{~cm}$ above the top of the columns, which produced a light intensity of $8 \mu \mathrm{mol}$ quanta $\mathrm{m}^{-2} \mathrm{~s}^{-1}$ at the water surface, similar to light levels at dawn or dusk, and comparable to the light levels used by Heuch (1995). Holes were set in the sides of the tank for hose attachment, allowing water to be constantly flushed through each half to control temperature. The outside was encased in a black covering to shield columns from any ambient light.

We created a series of different thermoclines at the mid-point of the column. The bottom layer was $12^{\circ} \mathrm{C}$ and the top layer varied with the following treatments: $6,8,10,12,14,16$ and $18^{\circ} \mathrm{C}$. For each temperature, we conducted 4 separate replicated column runs. The order of replicate runs was randomized across treatments.

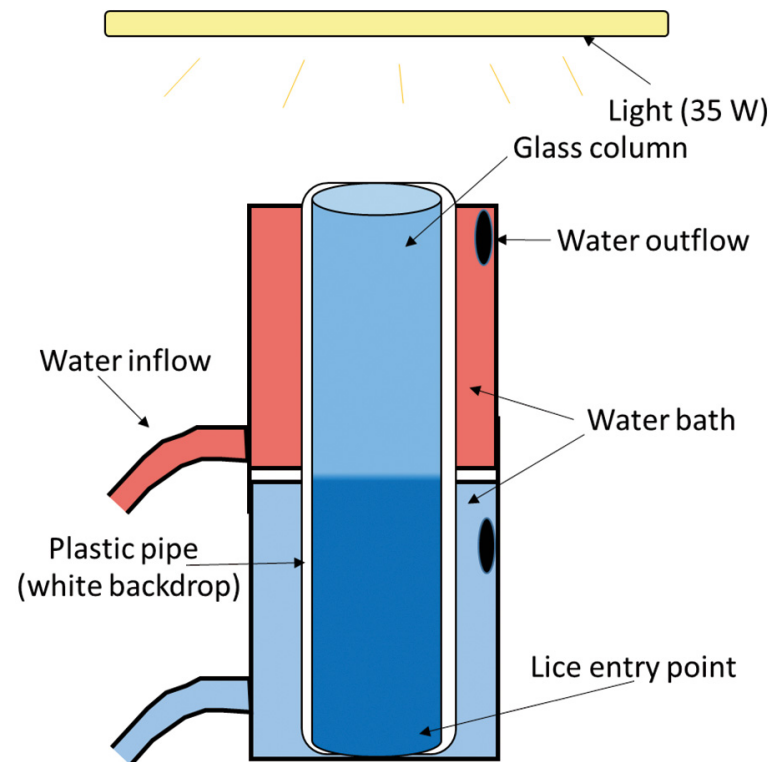

Fig. 1. Experimental column used to test the vertical distribution of nauplii and copepodid larvae in salinity gradients
Water of different temperatures used in the treatments was created by combining $20^{\circ} \mathrm{C}$ and $3^{\circ} \mathrm{C}$ from header tanks. The temperature was monitored through thermometers in the overhead tanks and adjusted to be within $0.5^{\circ} \mathrm{C}$ of the desired temperature. To counteract the tendency of cold water to sink, $32 \mathrm{ppt}$ water was used for the top layer and natural salinity (34.7 ppt) water for the bottom layer. Based on previous research on responses to salinity, the difference between the top and bottom layers was not expected to alter depth preferences of nauplii and copepodids (Crosbie et al. 2019). All salinities were checked and confirmed to 0.1 ppt using a Cond 315i handheld meter. The water mixture for the top layer was first poured into the column up to approximately halfway $(\sim 40 \mathrm{~cm})$. Afterwards a tube was lowered to the bottom and natural seawater (34.7 ppt) at $12^{\circ} \mathrm{C}$ was slowly pumped in via a peristaltic pump.

After a thermocline was established, approximately 100 lice of the appropriate stage were extracted from the incubators and then pumped into the bottom of the column via the peristaltic pump.

\subsection{Recording temperature preference of larvae}

After lice were introduced to the column, it was covered in black plastic. One hour after their entry, the position of all lice in the column was counted. The encasing cover was removed, and a more powerful fluorescent lamp fixed directly above the columns to increase lice visibility. We conducted a timed $2 \mathrm{~min}$ count by eye to record their positions to the nearest $\mathrm{cm}$ on a roll of paper placed against the side of the column. All nauplii were recorded without staging to nauplius I or II. This rapid count limited how far lice could move in response to the new light source. After recording, we measured the salinity and temperature every $5 \mathrm{~cm}$ in the column with a Cond 315i handheld meter to establish where the thermocline was located and its thickness.

\subsection{Statistical analysis}

To test if the proportion of nauplii and copepodids that migrated through the thermocline to the top layer differed among treatments, 1-way ANOVAs were performed to compare the proportion of lice in the top layer. Proportional data were logit-transformed prior to analyses and assumptions of the model were tested with diagnostic plots. Tukey's post hoc tests were 
used when significant differences were detected. To test if the proportion of nauplii and copepodids that aggregated at the point in the column immediately below the thermocline differed among treatments, we also used ANOVA and Tukey's post hoc tests.

\subsection{Modelling larval dispersal}

The Norwegian National Salmon Lice Dispersal Model (NSLDM) is a particle-tracking biologicalphysical dispersal model. Full details of the operation and parameterization of the model are given in Johnsen et al. $(2014,2016)$ and Samsing et al. (2016). To test how dispersal of nauplii differed when responses to temperature were parameterized with results from our column experiments, we ran a simulation of larvae dispersal in 2 coastal regions of Norway during 3 times of the year.

In the simulation, particles representing salmon lice during their planktonic stages were released every hour from 2 sites (an inner and an outer position within the fjord) around the Hardangerfjord $\left(\sim 60^{\circ} \mathrm{N}, 5.5^{\circ} \mathrm{E}\right)$ and 3 sites (inner, mid and outer) at Namsen $\left(\sim 65^{\circ} \mathrm{N}, 11^{\circ} \mathrm{E}\right)$ on the west coast of Norway. Simulations were run in January 2015, March 2016 and July 2016 in Hardangerfjord and April, July and August 2014 in Namsen. Environmental conditions or forcing parameters for the dispersal model (water currents, temperature and salinity) were provided by a hydrodynamic fjord model (Albretsen et al. 2011). The fjord model was set up for the study area to a horizontal resolution of $160 \times 160 \mathrm{~m}$ with 35 sigma layers in the vertical plane.

Lice in the model were given temperaturedependent development and the ability to migrate vertically in the water column in response to light and salinity. In previous model simulations (e.g. Johnsen et al. 2014, 2016), lice particles did not alter their vertical swimming in response to temperature differences in the water column. The results from the column experiments showed that nauplii do not swim upwards into warmer waters. We implemented this in the simulation by only allowing nauplii to swim upwards if the surface water was colder than below, and downwards towards the thermocline if the surface was warmer than below.

In all simulations, modelled lice particles became infective copepodids at 50 degree-days and had a total lifespan of 170 degree-days (Samsing et al. 2016). Mortality was parameterized at a constant rate of $17 \% \mathrm{~d}^{-1}$. The age and position of lice particles were stored every hour and used to calculate the density field of infective lice particles (i.e. copepodid particles).

\section{RESULTS}

\subsection{Migration above the thermocline}

Temperature strongly influenced the proportion of nauplii that moved into the top part of the column $(\mathrm{p}<0.0001)$. Post hoc analysis shows that the $12^{\circ} \mathrm{C}$ isothermal column had a lower lice percentage in the top half of the column (30\%) than columns with a $6^{\circ} \mathrm{C}$ overlying layer $(75 \%$; $\mathrm{p}=0.046$; Fig. $2 \mathrm{a})$. Further, the $12^{\circ} \mathrm{C}$ isothermal column had a higher percentage in the overlying layer than in the columns with overlying $18^{\circ} \mathrm{C}$ layers $(\mathrm{p}=0.03)$, indicating that both configurations of a warm-cold thermocline affected lice behaviour. In contrast to nauplii, overlying temperature did not influence the percentage of copepodids in the top half of the column ( $\mathrm{p}=0.6$; Fig. $2 \mathrm{~b}$ ). In all treatments, $70-80 \%$ of copepodids moved into the top half of the column.

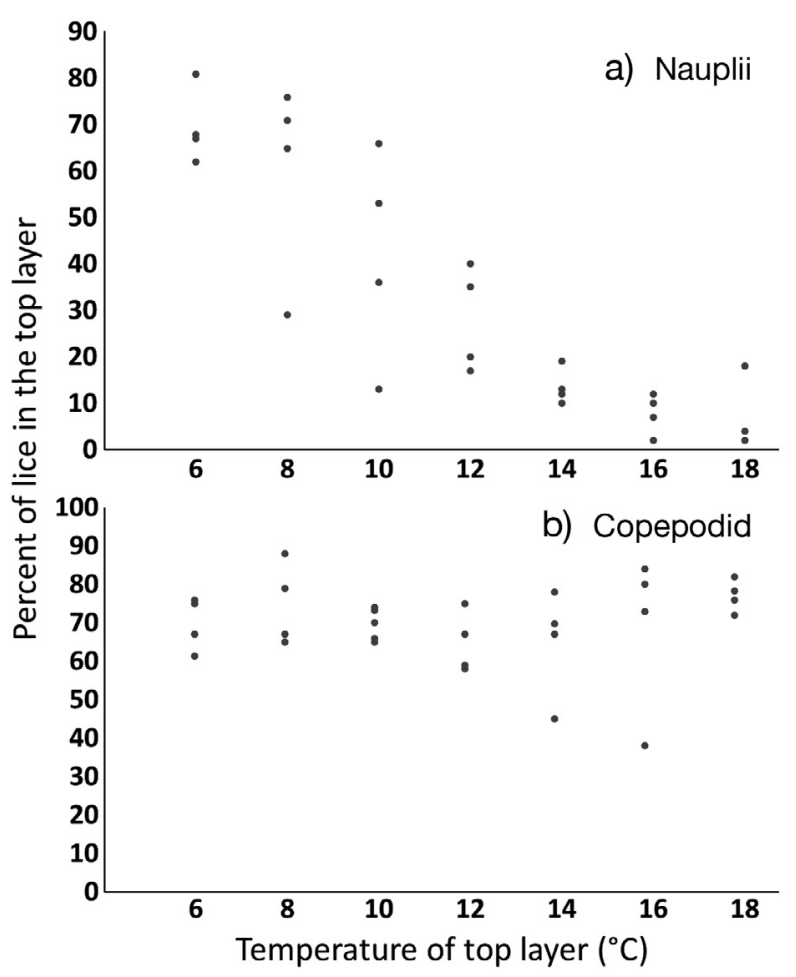

Fig. 2. Proportion of (a) nauplii and (b) copepodids of Lepeophtheirus salmonis in the layer above the step temperature gradient as a function of the temperature in the overlying layer. Each point represents the proportion of lice in the top layer for a column replicate. The $12^{\circ} \mathrm{C}$ treatment served as an isothermal control $\left(12^{\circ} \mathrm{C}\right.$ in both the top and bottom layers of the column) 


\subsection{Aggregation in the thermocline}

Nauplii aggregated in and immediately beneath the thermocline when the overlying layer was the warmer of the 2 layers (Fig. 3a), with the treatment with the $18^{\circ} \mathrm{C}$ overlying layer significantly differing from the isohaline $12^{\circ} \mathrm{C}$ column (Tukey's test: $\mathrm{p}=0.04$ ). For the 14 to $18^{\circ} \mathrm{C}$ treatments, 20 to $28 \%$ of lice positioned within the $10 \mathrm{~cm}$ of the column at and just below the thermocline. If they had been randomly distributed, only $12.5 \%$ would have been within any $10 \mathrm{~cm}$ section of the column. Where overlying layers were colder (6$10^{\circ} \mathrm{C}$ ) and nauplii mostly gathered at the top of the column, no aggregation around the thermocline in the middle of the column occurred (Fig. 3a).

Copepodids did not aggregate at the thermocline regardless of treatment $(p=0.5)$. Instead, their vertical distribution followed a consistent pattern across all temperatures tested, with the highest percentages at the top of the column, gradually declining to the lowest percentages in the bottom of the column (Fig. 3b).

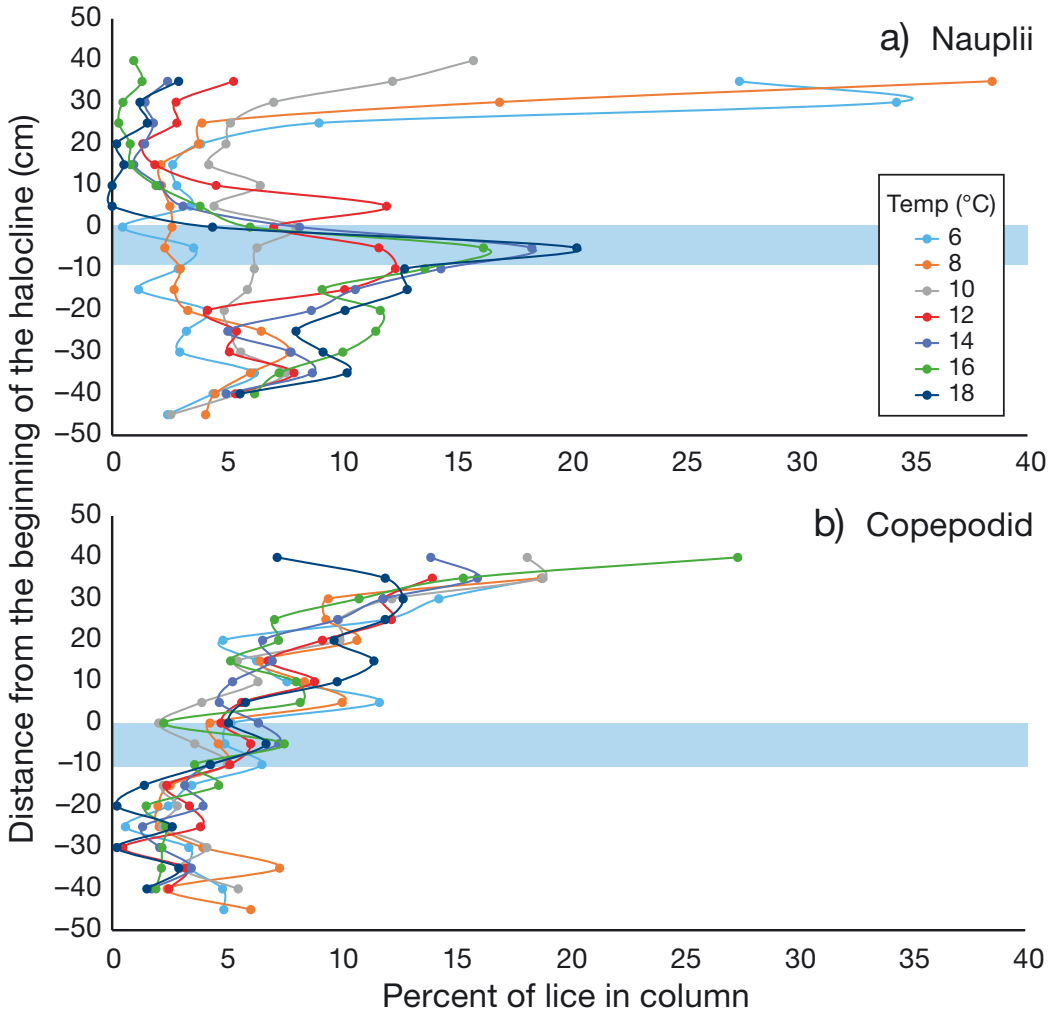

Fig. 3. Average proportion of (a) nauplii and (b) copepodids of Lepeophtheirus salmonis found in each $5 \mathrm{~cm}$ segment of the column relative to the thermocline for each temperature treatment. Shaded area: $10 \mathrm{~cm}$ over which the largest temperature change occurred. Each point represents the mean of 4 column replicates. The $12^{\circ} \mathrm{C}$ treatment served as an isothermal control $\left(12^{\circ} \mathrm{C}\right.$ in both the top and bottom layers of the column)

\subsection{Modelling larval dispersal}

We detected a small but consistent effect of including the larval behaviour of nauplii towards temperature in the dispersal model (Table 1). Depending upon location and time of year, dispersal distance at the 50-degree day point, where copepodids become infective, increased by $0.1-9.4 \%$ when the effects of temperature were included. Simulated particles from the original model were generally distributed higher in the water column compared to particles in the new model simulation.

\section{DISCUSSION}

We have demonstrated that nauplii and copepodids have markedly different behaviours in response to temperature step gradients, resulting in differing vertical distributions under light levels equivalent to dusk/dawn conditions. Nauplii displayed a preference for cooler water when given
Table 1 . Distance $(\mathrm{km})$ travelled by nauplii (0-50 degreedays) in different simulation scenarios in Hardanger and Namsen under the model where the effect of temperature on nauplii is not included (old model), and the model where the effect is included (new model). \% increase is the increase in dispersal distance under the new model relative to the old model

\begin{tabular}{|lrrc}
\hline Simulation site and time & $\begin{array}{c}\text { Old } \\
\text { model }\end{array}$ & $\begin{array}{c}\text { New } \\
\text { model }\end{array}$ & $\begin{array}{c}\% \\
\text { increase }\end{array}$ \\
\hline Hardanger, January 2015 & 152.1 & 161.5 & 6.2 \\
Hardanger, March 2016 & 135.5 & 139.0 & 2.6 \\
Hardanger, July 2016 & 80.1 & 86.1 & 7.5 \\
Namsen, April 2014 & 124.0 & 124.1 & 0.1 \\
Namsen, July 2014 & 45.8 & 50.1 & 9.4 \\
Namsen, August 2014 & 67.8 & 72.2 & 6.5 \\
\hline
\end{tabular}

the option between 2 layers of different temperature. Copepodids preferred the top layer regardless of temperature, indicating that factors other than temperature exert a much stronger influence on their vertical distribution. Because of the effect of temperature on development and longevity, our 
results have implications for dispersal model outcomes regarding the distance lice larvae travel from hatch location.

\subsection{Vertical distribution of nauplii in the presence of thermoclines}

During our experiments, nauplii that were introduced into the bottom of the column moved towards the top in greatest proportions when the overlying top half of the column was 2 to $6^{\circ} \mathrm{C}$ cooler than the bottom half. When the situation was reversed, and the overlying layer was 2 to $6^{\circ} \mathrm{C}$ warmer than the bottom, reduced proportions of nauplii moved towards the top, with the majority remaining at the thermocline or below.

Our experimental results run counter to field evidence of nauplii distribution from the Faroe Islands, where nauplii vertical distribution in a fjord with multiple salmon farms led á Norði et al. (2015) to suggest that nauplii seek the highest possible seawater temperature in the water column in the absence of salinity stratification. Nauplii develop faster and show more activity in warmer water (Pike \& Wadsworth 1999, Angilletta et al. 2004, Samsing et al. 2016). Like many other planktonic marine organisms, quicker growth would allow them to more quickly reach maturity and start reproduction, which can be an important fitness benefit in the face of high daily mortality (Thorson 1950, Reitzel et al. 2004). Given these effects of temperature, we had expected warmer water to be attractive to lice larvae when given a choice between 2 different temperatures.

Several possible explanations exist for the unexpected result we obtained. First, the distribution of nauplii in field collections (e.g. á Norði et al. 2015) are likely influenced by the swimming depths of salmon infected with adult female lice. Salmon display a strong preference to swim at depths where temperatures are warmest, up to $16^{\circ} \mathrm{C}$ (Oppedal et al. 2011). In systems dominated by farmed salmon where plankton collection points are within the vicinity of farms shedding many nauplii larvae, nauplii distribution in water column samples may largely mirror salmon swimming depths in cages.

Second, because of a smaller density differential between the medium and the organism, nauplii within colder or more saline water are more buoyant, sink at a slower rate and therefore would need to swim upwards less to maintain their position in the water column. As a result, nauplii may better conserve energy while they develop, leaving more to be used in growth, predator avoidance or during the copepodid stage when reserves deplete, and host attachment becomes critical to further survival.

Third, the universal 'temperature-size relationship' among ectotherms describes that in colder temperatures, organisms will grow at a slower rate but will attain a larger body size at maturity (Angilletta et al. 2004). Salmon lice are no exception to this rule (Samsing et al. 2016). Larger body size and more energy reserves upon reaching the copepodid stage may confer advantage in terms of greater capacity to sense and attach to a host and/or greater energy reserves may allow for more time in the water column to encounter a host. Larger invertebrate larvae typically have better post-settlement survival (Marshall et al. 2003); this may also hold true for lice.

Fourth, during winter months, there are very few wild hosts in coastal areas, as sea trout Salmo trutta move into rivers (Klemetsen et al. 2003, Jonsson \& Jonsson 2009) and salmon are either in the open ocean or travelling upstream to spawn (Hansen \& Quinn 1998, Heuch et al. 2002). Because long-term exposure to brackish water is lethal for lice, limited larval production occurs over winter. Delaying growth in colder water gives larvae hatching in winter more time and a greater chance to meet a host or survive until seasonal changes cause wild hosts to return to fjords and coastal regions. Longer development time in the plankton at colder temperatures would expose nauplii to increased predation risk. However, colder waters of $6-8^{\circ} \mathrm{C}$ are indicative of winter temperatures over much of Norway, where predation rates on plankton are typically lower than in the warmer spring-summer plankton bloom season (Eilertsen \& Taasen 1984). This could offset the risk of a longer development time.

Fifth, avoidance of warmer waters could increase dispersal distances, through both slower development to the infective copepodid stage and vertical position in the water column, which could combine to create a longer planktonic period. The preference nauplii exhibited for colder waters modified their dispersal distances by altering their depth in the water column, which in turn affects their exposure to depth-dependent oceanographic processes and the duration of their temperature-dependent development. Modelled outcomes that included the response of nauplii to temperature were always towards a greater overall dispersal distance (Table 1), supporting the hypothesis that temperature preferences exhibited by nauplii assist in maximizing dispersal. Greater dispersal has multiple possible advantages for marine invertebrates (Pechenik 1999), including 
decreased likelihood of inbreeding and an increased ability to withstand local extinction.

Salmon lice larvae are unable to properly develop below a minimum temperature of $\sim 3-5^{\circ} \mathrm{C}$ (Boxaspen 2006, Samsing et al. 2016, Hamre et al. 2019). The lowest temperature we tested was $6^{\circ} \mathrm{C}$; lice preferences could change once the minimum threshold is approached. Lice tolerances also depend on the conditions they were bred from (Boxaspen \& Næss 2000), as populations become adapted to the norms of their latitude. For the present experiment, wild adult lice were collected from a commercial farm in Masfjorden in southwestern Norway, which experiences a broad range of surface temperatures across a year $\left(\sim 1\right.$ to $\left.20^{\circ} \mathrm{C}\right)$. All larvae were bred and incubated at $12^{\circ} \mathrm{C}$. Using different strains or a different incubation temperature could have changed the vertical distribution patterns we observed.

Mapping proportions in each region of the column showed that nauplii only grouped around a thermocline as they started to avoid the layer above the temperature step gradient when temperatures were 14, 16 and $18^{\circ} \mathrm{C}$. In the cooler treatments, when nauplii rose predominantly into the top of the overlying layer, the thermocline did not influence their vertical distribution. In an isothermal situation, there was a larger percentage of lice at the midpoint of the column, probably due to the slight halocline we established. However, aggregations were larger at the stronger haloclines established in columns in Crosbie et al. (2019). Aggregations at the halocline also occurred for copepodids in that study, indicating that step salinity gradients invoke a greater response in salmon lice than temperature step gradients.

\subsection{Vertical distribution of copepodids in the presence of thermoclines}

Copepodids showed no preference for temperature. High proportions swam to the overlying layer $(60-80 \%)$ in all temperatures, with no evidence of aggregation at the temperature step gradient. The most likely reason why copepodids behave differently to nauplii is that they position vertically to maximize host encounters. Copepodids must attach to a suitable host (principally Atlantic salmon, brown trout, and Arctic charr Salvelinus alpinus) before their energy reserves deplete (Tucker et al. 2002). All host species are anadromous, spawning in freshwater rivers and migrating out to sea as smolts during springtime (Stien et al. 2005, Davidsen et al. 2009, Thorstad et al. 2012). During their migration, smolts swim in the top few metres of the water column (LaBar et al. 1978, Plantalech ManelLa et al. 2009), a strategy that means they often travel within layers of freshwater river discharge, potentially reducing infection rates (McCormick et al. 1998). In cages, post-smolts choose a swimming depth that coincides with haloclines if these are present in the months after seawater transfer, possibly with similar effect (Oppedal et al. 2011). Adult salmon position vertically predominantly in response to light and temperature, often swimming deep during daytime (especially in spring and summer) and close to the surface at night (Fernö et al. 1995, Oppedal et al. 2011). Unlike post-smolts, larger fish have a smaller response to salinity after 3 mo in the sea (Oppedal et al. 2011). Brown trout that out-migrate to saltwater largely remain in waters near the coast (Jonsson 1985, Klemetsen et al. 2003) and spend $>90 \%$ of their time close to the surface (Rikardsen et al. 2007).

To increase their success of infesting a host, the vertical response of copepodids to environmental variables must maximize host detection and attachment. Their responses to light and salinity cues cause them to inhabit similar depths to out-migrating smolts, farmed salmon or feeding sea trout. Further, their diurnal migration means that lice will encounter adult salmon ascending at dusk. Because light cues help with host-finding, any possible preference for temperature may be overridden by response to light as an environmental driver (Novales Flamarique et al. 2000), as evidenced by attraction to light at the top of the column at all temperatures in our experiment. Copepodids also respond to salinity, with distinct aggregation within haloclines that may heighten their chance to interact with smolts or adults navigating through step gradients (Crosbie et al. 2019).

An additional reason for the different results between nauplii and copepodids is that copepodid morphology and size allow them to be more efficient swimmers than nauplii (Andersen Borg et al. 2012, Allen \& Lewis 2013). Their larger appendages can also create greater drag and reduce their sinking rate (Allen \& Lewis 2013). Both factors would mean that copepodids are less reliant on positioning themselves in denser water to save energy while maintaining their depth. As with the nauplii, the temperatures we tested were within the typical temperature range experienced by copepodids in the sea and did not approach thermal minima or maxima. Vertical swimming responses to temperature gradients may alter for extremely warm and cold temperatures and should be tested in future. 


\subsection{Implications for salmon lice larvae dispersal modelling}

Coupled oceanographic biological models to estimate lice dispersal use depth-based temperature profiles as a determinate of how long larvae remain in the pelagic phase before they attach to a host or die (Myksvoll et al. 2018). However, temperature has not previously been factored into the biological side of these models as an influence on vertical distribution patterns (e.g. Johnsen et al. 2014), with salinity and light regarded as having greater importance. Our results reinforce the lack of influence of temperature on copepodid vertical distribution, in contrast to their more nuanced responses to salinity (Heuch 1995, Crosbie et al. 2019) and light levels (Heuch et al. 1995, Novales Flamarique et al. 2000, Szetey 2019). The stronger responses of nauplii towards colder temperatures and avoidance of warmer temperatures produced small changes in dispersal in 2 typical coastal regions. These changes were unidirectional towards greater dispersal. The modelling scenarios indicate that more accurate patterns of dispersal can be achieved if temperature is simulated to affect vertical distribution.

\section{CONCLUSION}

Our results revealed substantial differences in the way that planktonic salmon lice larvae of different stages respond to temperature, which likely reflect stage-dependent life-history strategies. The results extend our understanding that nauplii and copepodids display different behaviours towards environmental cues and extend the results of Crosbie et al. (2019), who demonstrated markedly different behavioural responses of nauplii and copepodids to salinity gradients in the water column. Our results will better inform approaches to prevent salmon lice infestation in salmon farms with depth-based shielding technologies (e.g. skirts: Stien et al. 2018; snorkels: Wright et al. 2017, Geitung et al. 2019) and improve combined hydrodynamic-biological models that predict salmon lice dispersal for management purposes (e.g. Johnsen et al. 2014, Myksvoll et al. 2018, Samsing et al. 2019).

Small-scale column experiments are useful as they enable controlled conditions and an ability to replicate appropriately to draw out differences towards environmental conditions. However, small columns cannot accurately recreate all processes that may interact with environmental variables such as light, temperate and salinity and prove influential to the vertical distribution of lice larvae. For example, copepodid larvae appear to respond to pressure changes (Bron et al. 1993), with increased upwards burst swimming displayed when larvae were subjected to pressures equivalent to $4-5 \mathrm{~m}$ depth. Further, few sea lice larvae have been recorded at depth in the ocean in field surveys (Johannessen 1978, J. Costelloe et al. 1995, M. Costelloe et al. 1998, McKibben \& Hay 2004). Behavioural responses to light (e.g. Heuch et al. 1995), temperature (the present paper) and salinity (Crosbie et al. 2019) obtained at small column scale require ground-truthing in large-scale columns or natural environments to test if vertical distribution patterns hold when pressures are realistic.

Acknowledgements. We thank the staff at the Institute of Marine Research Matre Station for technical assistance during the experiment, including Ivar Helge Matre, Tone Vågseth and Simon Flavell. Thanks to Luke Barrett and Michael Sievers for assistance in collecting lice. Funding was provided by the Norwegian Seafood Research Fund to project \#901283 'Utvikling av lakselus ved ulik temperatur og lys (TEMPLUS)'.

\section{LITERATURE CITED}

Norði G, Simonsen K, Danielsen E, Eliasen K and others (2015) Abundance and distribution of planktonic Lepeophtheirus salmonis and Caligus elongatus in a fish farming region in the Faroe Islands. Aquacult Environ Interact 7:15-27

Aarseth KA, Schram TA (1999) Wavelength-specific behaviour in Lepeophtheirus salmonis and Calanus finmarchicus to ultraviolet and visible light in laboratory experiments (Crustacea: Copepoda). Mar Ecol Prog Ser 186: 211-217

Albretsen K, Sperrevik AK, Staalstrøm A, Sandvik AD, Vikebø F, Asplin L (2011). NorKyst-800 Rep No. 1: User manual and technical descriptions. Fisken og Havet 02/2011. Institute of Marine Research, Bergen

Allen SE, Lewis AG (2013) Lepeophtheirus salmonis (Krøyer, 1837): second nauplius and copepodid locomotor appendages, surface areas and possible appendage functions. Crustaceana 86:1695-1710

Andersen Borg CM, Bruno E, Kiørboe T (2012) The kinematics of swimming and relocation jumps in copepod nauplii. PLOS ONE 7:e47486

Angilletta MJ, Steury TD, Sears MW (2004) Temperature, growth rate, and body size in ectotherms: fitting pieces of a life-history puzzle. Integr Comp Biol 44:498-509

Boxaspen K (2006) A review of the biology and genetics of sea lice. ICES J Mar Sci 63:1304-1316

*Boxaspen K, Næss T (2000) Development of eggs and the planktonic stages of salmon lice (Lepeophtheirus salmonis) at low temperatures. Contrib Zool 69:51-55

Bron JE, Sommerville C, Rae GH (1993) Aspects of the behaviour of copepodid larvae of the salmon louse Lepeophtheirus salmonis (Krøyer, 1837). In: Boxshall GA, 
Defaye D (eds) Pathogens of wild and farmed fish: sea lice. Ellis Harwood, Chichester, p 125-142

Costello MJ (2006) Ecology of sea lice parasitic on farmed and wild fish. Trends Parasitol 22:475-483

* Costelloe J, Costelloe M, Roche N (1995) Variation in sea lice infestation on Atlantic salmon smolts in Killary Harbour, west coast of Ireland. Aquacult Int 3:379-393

* Costelloe M, Costelloe J, O'Donohoe G, Coghlan NJ, Oonk M, Van der Heijden Y (1998) Planktonic distribution of sea lice larvae, Lepeophtheirus salmonis, in Killary Harbour, west coast of Ireland. J Mar Biol Assoc UK 78:853-874

* Crosbie T, Wright DW, Oppedal F, Johnsen IA, Samsing F, Dempster T (2019) Effects of step salinity gradients on salmon lice larvae behaviour and dispersal. Aquacult Environ Interact 11:181-190

Davidsen JG, Rikardsen AH, Halttunen E, Thorstad EB and others (2009) Migratory behaviour and survival rates of wild northern Atlantic salmon Salmo salar post-smolts: effects of environmental factors. J Fish Biol 75:1700-1718

Eilertsen HC, Taasen JP (1984) Investigations on the plankton community of Balsfjorden, Northern Norway. Sarsia 69:1-15

Fernö A, Huse I, Juell JE, Bjordal Å (1995) Vertical distribution of Atlantic salmon (Salmo salar L.) in net pens: tradeoff between surface light avoidance and food attraction. Aquaculture 132:285-296

* Geitung L, Oppedal F, Stien LH, Dempster T, Karlsbakk E, Nola V, Wright DW (2019) Snorkel sea-cage technology decreases salmon lice infestation by $75 \%$ in a full-cycle commercial test. Int J Parasitol 49:843-846

KHamre LA, Eichner C, Caipang CMA, Dalvin ST and others (2013) The salmon louse Lepeophtheirus salmonis (Copepoda: Caligidae) life cycle has only two chalimus stages. PLOS ONE 8:e73539

*Hamre L, Bui S, Oppedal F, Skern-Mauritzen R, Dalvin S (2019) Development of the salmon louse Lepeophtheirus salmonis parasitic stages in temperatures ranging from 3 to $24^{\circ} \mathrm{C}$. Aquacult Environ Interact 11:429-443

Haney JF (1988) Diel patterns of zooplankton behavior. Bull Mar Sci 43:583-603

*Hansen LP, Quinn TP (1998) The marine phase of the Atlantic salmon (Salmo salar) life cycle, with comparisons to Pacific salmon. Can J Fish Aquat Sci 55:104-118

Hays GC (2003) A review of the adaptive significance and ecosystem consequences of zooplankton diel vertical migrations. Hydrobiologia 503:163-170

*Heuch PA (1995) Experimental evidence for aggregation of salmon louse copepodids (Lepeophtheirus salmonis) in step salinity gradients. J Mar Biol Assoc UK 75:927-939

*Heuch PA, Parsons A, Boxaspen K (1995) Diel vertical migration: a possible host-finding mechanism in salmon louse (Lepeophtheirus salmonis) copepodids? Can J Fish Aquat Sci 52:681-689

Heuch PA, Knutsen JA, Knutsen H, Schram TA (2002) Salinity and temperature effects on sea lice over-wintering on sea trout (Salmo trutta) in coastal areas of the Skagerrak. J Mar Biol Assoc UK 82:887-892

Huntley M, Brooks ER (1982) Effects of age and food availability on diel vertical migration of Calanus pacificus. Mar Biol 71:23-31

Johannessen A (1978) Early stages of Lepeophtheirus salmonis (Copepoda: Caligidae). Sarsia 63:169-176

Johnsen IA, Fiksen Ø, Sandvik AD, Asplin L (2014) Vertical salmon lice behaviour as a response to environmental conditions and its influence on regional dispersion in a fjord system. Aquacult Environ Interact 5:127-141

* Johnsen IA, Asplin LC, Sandvik AD, Serra-Llinares RM (2016) Salmon lice dispersion in a northern Norwegian fjord system and the impact of vertical movements. Aquacult Environ Interact 8:99-116

Johnson SC, Albright LJ (1991) The developmental stages of Lepeophtheirus salmonis (Krøyer, 1837) (Copepoda: Caligidae). Can J Zool 69:929-950

Jonsson B (1985) Life history patterns of freshwater resident and sea-run migrant brown trout in Norway. Trans Am Fish Soc 114:182-194

* Jonsson B, Jonsson N (2009) Migratory timing, marine survival and growth of anadromous brown trout Salmo trutta in the River Imsa, Norway. J Fish Biol 74:621-638

Klemetsen A, Amundsen PA, Dempson JB, Jonsson B, Jonsson N, O'Connell MF, Mortensen E (2003) Atlantic salmon Salmo salar L., brown trout Salmo trutta L. and Arctic charr Salvelinus alpinus (L.): a review of aspects of their life histories. Ecol Freshw Fish 12:1-59

* LaBar GW, McCleave JD, Fried SM (1978) Seaward migration of hatchery-reared Atlantic salmon (Salmo salar) smolts in the Penobscot River estuary, Maine: openwater movements. ICES J Mar Sci 38:257-269

Lampert W (1993) Ultimate causes of diel vertical migration of zooplankton: new evidence for the predator-avoidance hypothesis. Arch Hydrobiol Beih 39:79-88

*Marshall DJ, Bolton TF, Keough MJ (2003) Offspring size affects the post-metamorphic performance of a colonial marine invertebrate. Ecology 84:3131-3137

* Mauchline J (1998) The biology of calanoid copepods. Adv Mar Biol 33:1-518

* McCormick SD, Hansen LP, Quinn TP, Saunders RL (1998) Movement, migration, and smolting of Atlantic salmon (Salmo salar). Can J Fish Aquat Sci 55:77-92

* McKibben MA, Hay DW (2004) Distributions of planktonic sea lice larvae Lepeophtheirus salmonis in the inter-tidal zone in Loch Torridon, Western Scotland in relation to salmon farm production cycles. Aquacult Res 35:742-750

McLaren IA (1963) Effects of temperature on growth of zooplankton, and the adaptive value of vertical migration. J Fish Res Board Can 20:685-727

Myksvoll MS, Sandvik AD, Albretsen J, Asplin L and others (2018) Evaluation of a national operational salmon lice monitoring system-from physics to fish. PLOS ONE 13: e0201338

*Novales Flamarique I, Browman HI, Bélanger M, Boxaspen $\mathrm{K}$ (2000) Ontogenetic changes in visual sensitivity of the parasitic salmon louse Lepeophtheirus salmonis. J Exp Biol 203:1649-1657

* O'Connor MI, Bruno JF, Gaines SD, Halpern BS, Lester SE, Kinlan BP, Weiss JM (2007) Temperature control of larval dispersal and the implications for marine ecology, evolution, and conservation. Proc Natl Acad Sci USA 104: 1266-1271

\% Oppedal F, Dempster T, Stien LH (2011) Environmental drivers of Atlantic salmon behaviour in sea-cages: a review. Aquaculture 311:1-18

* Pechenik JA (1999) On the advantages and disadvantages of larval stages in benthic marine invertebrate life cycles. Mar Ecol Prog Ser 177:269-297

* Pike AW, Wadsworth SL (1999) Sealice on salmonids: their biology and control. Adv Parasitol 44:233-337

* Plantalech Manel-La N, Thorstad EB, Davidsen JG, Økland F, Sivertsgård R, Mckinley RS, Finstad B (2009) Vertical movements of Atlantic salmon post-smolts relative to 
measures of salinity and water temperature during the first phase of the marine migration. Fish Manag Ecol 16: 147-154

Reitzel AM, Miner BG, McEdward LR (2004) Relationships between spawning date and larval development time for benthic marine invertebrates: a modeling approach. Mar Ecol Prog Ser 280:13-23

Rikardsen AH, Diserud OH, Elliott JM, Dempson JB, Sturlaugsson J, Jensen AJ (2007) The marine temperature and depth preferences of Arctic charr (Salvelinus alpinus) and sea trout (Salmo trutta), as recorded by data storage tags. Fish Oceanogr 16:436-447

Samsing F, Oppedal F, Dalvin S, Johnsen I, Vågseth T, Dempster T (2016) Salmon lice (Lepeophtheirus salmonis) development times, body size, and reproductive outputs follow universal models of temperature dependence. Can J Fish Aquat Sci 73:1841-1851

Samsing F, Johnsen IA, Treml EA, Dempster T (2019) Identifying 'firebreaks' to fragment connectivity networks of a marine parasite. Int J Parasitol 49:277-286

Stien A, Bjørn PA, Heuch PA, Elston DA (2005) Population dynamics of salmon lice Lepeophtheirus salmonis on Atlantic salmon and sea trout. Mar Ecol Prog Ser 290: 263-275

Stien LH, Lind MB, Oppedal F, Wright DW, Seternes T (2018) Skirts on salmon production cages reduced salmon lice infestations without affecting fish welfare. Aquaculture 490:281-287

Szetey A (2019) Salmon lice nauplii and copepodids display

Editorial responsibility: Bengt Finstad,

Trondheim, Norway different vertical migration patterns in response to light. MSc thesis, University of Melbourne

Thorson G (1950) Reproductive and larval ecology of marine bottom invertebrates. Biol Rev Camb Philos Soc 25:1-45

* Thorstad EB, Whoriskey F, Uglem I, Moore A, Rikardsen AH, Finstad B (2012) A critical life stage of the Atlantic salmon Salmo salar: behaviour and survival during the smolt and initial post-smolt migration. J Fish Biol 81: $500-542$

Tucker CS, Norman R, Shinn AP, Bron JE, Sommerville C, Wootten R (2002) A single cohort time delay model of the life-cycle of the salmon louse Lepeophtheirus salmonis on Atlantic salmon Salmo salar. Fish Pathol 37:107-118

Tully O (1992) Predicting infestation parameters and impacts of caligid copepods in wild and cultured fish populations. Invertebr Reprod Dev 22:91-102

Turner JT (2004) The importance of small pelagic planktonic copepods and their role in pelagic marine food webs. Zool Stud 43:255-266

*Wootten R, Smith JW, Needham EA (1982) Aspects of the biology of the parasitic copepods Lepeophtheirus salmonis and Caligus elongatus on farmed salmonids, and their treatment. Proc R Soc Edinb B Biol 81:185-197

Wright DW, Stien LH, Dempster T, Vågseth T, Nola V, Oppedal F (2017) 'Snorkel' lice barrier technology reduced two co-occurring parasites, the salmon louse (Lepeophtheirus salmonis) and the amoebic gill disease causing agent (Neoparamoeba perurans), in commercial salmon sea-cages. Prev Vet Med 140:97-105

Submitted: August 5, 2019; Accepted: November 8, 2019 Proofs received from author(s): December 19, 2019 